\title{
Clinical Study \\ Prehospital Intubation in Patients with Isolated Severe Traumatic Brain Injury: A 4-Year Observational Study
}

\author{
Mazin Tuma, ${ }^{1}$ Ayman El-Menyar, ${ }^{2,3}$ Husham Abdelrahman, ${ }^{1}$ Hassan Al-Thani, ${ }^{1}$ Ahmad \\ Zarour, ${ }^{1}$ Ashok Parchani, ${ }^{1}$ Sherwan Khoshnaw, ${ }^{1}$ Ruben Peralta, ${ }^{1}$ and Rifat Latifi ${ }^{1,3,4}$ \\ ${ }^{1}$ Department of Surgery, Section of Trauma Surgery, Hamad General Hospital (HGH), P.O. Box 3050, Doha, Qatar \\ ${ }^{2}$ Clinical Research, Section of Trauma Surgery, HGH, P.O. Box 3050, Doha, Qatar \\ ${ }^{3}$ Clinical Medicine, Weill Cornell Medical School, P.O. Box 24144, Doha, Qatar \\ ${ }^{4}$ Department of Surgery, University of Arizona, P.O. Box 245005, Tucson, AZ, USA
}

Correspondence should be addressed to Mazin Tuma; mazin615@yahoo.com

Received 3 August 2013; Revised 8 October 2013; Accepted 19 October 2013; Published 16 January 2014

Academic Editor: Peter J. Papadakos

Copyright (C) 2014 Mazin Tuma et al. This is an open access article distributed under the Creative Commons Attribution License, which permits unrestricted use, distribution, and reproduction in any medium, provided the original work is properly cited.

\begin{abstract}
Objectives. To study the effect of prehospital intubation (PHI) on survival of patients with isolated severe traumatic brain injury (ISTBI). Method. Retrospective analyses of all intubated patients with ISTBI between 2008 and 2011 were studied. Comparison was made between those who were intubated in the PHI versus in the trauma resuscitation unit (TRU). Results. Among 1665 TBI patients, 160 met the inclusion criteria (105 underwent PHI, and 55 patients were intubated in TRU). PHI group was younger in age and had lower median scene motor GCS $(P=0.001)$. Ventilator days and hospital length of stay $(P=0.01$ and 0.006 , resp. $)$ were higher in TRUI group. Mean ISS, length of stay, initial blood pressure, pneumonia, and ARDS were comparable among the two groups. Mortality rate was higher in the PHI group (54\% versus $31 \%, P=0.005$ ). On multivariate regression analysis, scene motor GCS (OR 0.55; 95\% CI 0.41-0.73) was an independent predictor for mortality. Conclusion. PHI did not offer survival benefit in our group of patients with ISTBI based on the head AIS and the scene motor GCS. However, more studies are warranted to prove this finding and identify patients who may benefit from this intervention.
\end{abstract}

\section{Introduction}

Prehospital intubation (PHI) is a standard approach for early critical care management among severe trauma patients. In particular, establishment of definitive airway is an integral part in the optimal care and management of severe traumatic brain injury (STBI) patients [1]. Several data showed that early prevention of hypoxia at the scene has favorable effect on the survival in patients with STBI [2-5]. An earlier study demonstrated that PHI in isolated STBI patients significantly reduced the mortality from $50 \%$ to $23 \%$, with an absolute survival benefit of $27 \%$ [6]. However, other data found PHI in head injury patients to be associated with worse outcomes [7-10], even with the use of Rapid Sequence Intubation (RSI) [11]. Many factors have been postulated to be responsible for such adverse outcome. These factors include higher risk of aspiration pneumonia, the effect of laryngoscopy on raising the intracranial pressure, the deleterious effect of hyperventilation and hypocapnia, and the potentially harmful effect of supra normal oxygen tension (hyperoxia) on the injured brain [12-15]. Helm et al. [16], in a prospective study, evaluated the effect of quality of controlled ventilation and airway protection in head injury patients. The authors did not find PHI effective for maintaining optimal oxygenation and ventilation in these patients. Despite high incidence of head injuries, the impact of PHI has not been extensively studied in our region. The aim of the present study is to evaluate the effect of prehospital intubation on the outcome of isolated STBI patients in Qatar.

\section{Methods}

2.1. Type of the Study. A retrospective cohort study over period of 4 years from January 2008 to December 2011 was conducted. 
2.2. Setting. Hamad General Hospital (HGH) is the only tertiary health care center, with a dedicated state of the art Trauma Center and Emergency Medical Services (EMS) equipped with ground and air ambulance services that covers a population of about 1.7 million in Qatar. Our EMS service is following up-to-date evidence-based standard treatment protocols and is staffed by critical care paramedics as well as Emergency Medical Technicians (EMT). Prehospital intubation is conducted exclusively by well-trained critical care paramedics (CCP). Qatar Emergency Medical Services has developed educational modules for training CCP in collaboration with external training agencies. A CCP program was established to provide additional clinical skills and expertise and support the improvement of clinical practice throughout HMC Ambulance Service. All CCPs were trained at the HMC-EMS. The training program includes RSI, surgical airway, needle thoracentesis, diagnostic and therapeutic emergency cardiac procedures, the application of a comprehensive critical care medication formulary, and the management of critical care patients during transfer.

Data were extracted from computer database registry. The registry records included demographic data, as well as scene vital signs, Glasgow Coma Score (GCS), motor component of GCS (coded between 1 and 6) [17], and intubation data. In addition, the modes of transportation, mechanism of injury, admission vital signs, head AIS score, injury severity score (ISS), and outcome were also collected. All trauma patients were managed according to advanced trauma life support (ATLS) principles and trauma brain foundation guidelines [18] as appropriate.

2.3. Inclusion Criteria. All adult patients of age $>14$ years are admitted to HGH who required intubation based on GCS and head AIS. Patients with isolated STBI were identified as head Abbreviated Injury Score (AIS) $\geq 3$ with no other regions of AIS $>3$ and field GCS score $\leq 8$ [7].

All patients were divided into two groups according to the place of intubation: group 1 (intubated at the scene; $\mathrm{PHI}$ ) and group 2 (intubated in the resuscitation room; TRUI).

2.4. Exclusion Criteria. We excluded patients who died within 24 hours after injury (in whom the cause of death may be due to life-threatening hemorrhage or unclear cause), patients who transferred from other hospitals, or those who were intubated in the operating room or intensive care unit.

2.5. Primary End Point. All-cause mortality is within 30 days after admission.

2.6. Ethical Approval. This study was approved by the Medical Research Center (IRB no. 12134/12) at Hamad Medical Corporation, Qatar.

2.7. Statistical Analysis. Data were presented as proportions or mean \pm standard deviation (SD) as appropriate. Baseline demographic characteristics, presentation, management, and outcomes were compared between the two groups using the
Student's $t$-test for continuous variables and Pearson chisquare $\left(\chi^{2}\right)$ test for categorical variables. Multivariate logistic regression was used to calculate the odds ratio for prediction of mortality. A significant difference was considered when the $P$ value was less than 0.05 . Data analysis was carried out using the Statistical Package for Social Sciences version 18 (SPSS Inc., Chicago, USA).

\section{Results}

During the study period, there were 1665 patients admitted with diagnosis of traumatic brain injury. Only 160 patients had ISTBI (defined by GCS score $\leq 8$ and head AIS score $\geq 3$ ) and intubation was carried on for all. 105 (66\%) were intubated in the prehospital settings (PHI group) and 55 (34\%) were intubated in the trauma resuscitation room (TRUI group) (Table 1). All cases were intubated orally using RSI. Most patients were males with mean age of $31 \pm 14$ years. Traffic related injuries were the predominant mechanism of injury. Overall median motor component of GCS was 1(1-6) and the overall mortality rate was $46 \%$ (Table 1).

Patients in PHI group were younger in age and had significantly lower median scene motor GCS $[1(1-5)$ versus $3(1-5) ; P=0.001]$. Majority of patients in TRUI group were transported to the hospital by ground EMS ( $98 \%$ versus $76 \%$; $P=0.001$ ) (Table 1), whereas helicopter was used to transport more patients in PHI group (24\% versus 2\%; $P=0.001$ ). Further, oxygen saturation, systolic blood pressure, and pulse rates were comparable among the two groups. More patients in TRUI group underwent craniotomy (25\% versus 6\%; $P=$ $0.001)$. Ventilator days [5(1-29) versus $3(1-19) ; P=0.014]$ and hospital length of stay [22(1-410) versus 9(1-380); $P=$ 0.006] were significantly higher in TRUI group. The mean ISS, ICU length of stay, initial blood pressure, blood alcohol levels, and complication rate (pneumonia and ARDS) were comparable among the two groups (Table 1). The mortality rate was significantly higher in the PHI group (54\% versus $31 \%, P=0.005$ ) (Table 1). On multivariate regression analysis after adjusting for covariates (age, ISS, motor GCS, place of intubation, and EMS time), scene motor GCS (OR 0.55; $95 \%$ CI $0.41-0.73$ ) was found to be an independent predictor for mortality (Table 2).

\section{Discussion}

This study demonstrates that the overall mortality rate in severe traumatic brain injury patients is about $46 \%$ based on the head AIS $\geq 3$ and GCS $\leq 8$. This finding is consistent with other academic centers that follow brain trauma foundation guidelines in the management of severe traumatic brain injury [23]. In the current study, low motor component of GCS was an independent predictor of mortality in intubated ISTBI patients regardless of the place of intubation. Table 3 shows a review of literature for prehospital intubation in severe traumatic head injury patients $[6,7,9,19-22]$. Prehospital intubation of severely injured patients who cannot maintain adequate airway is common practice worldwide. Such practice, however, has not improved the outcomes in 
TABLE 1: Demographics of all intubated isolated severe traumatic brain injury cases.

\begin{tabular}{|c|c|c|c|c|}
\hline & $\begin{array}{c}\text { All intubated } \\
\quad n=160\end{array}$ & $\begin{array}{c}\text { Prehospital intubation } \\
\quad n=105(65 \%)\end{array}$ & $\begin{array}{c}\text { TRU intubation } \\
n=55(34 \%)\end{array}$ & $P$ value \\
\hline Age (yrs; mean \pm SD) & $31 \pm 14$ & $30 \pm 14$ & $34 \pm 15$ & 0.14 \\
\hline Males (\%) & 96.5 & 95 & 98 & 0.35 \\
\hline \multicolumn{5}{|l|}{ Nationality } \\
\hline Qatari (\%) & 22 & 20 & 23 & \multirow[t]{2}{*}{0.27 for all } \\
\hline Non-Arab (\%) & 78 & 80 & 77 & \\
\hline \multicolumn{5}{|l|}{ Mechanism of injury } \\
\hline Fall from height (\%) & 12 & 13.5 & 11 & \multirow{2}{*}{0.92 for all } \\
\hline Traffic related injuries (\%) & 81 & 79 & 83 & \\
\hline Fall of heavy object (\%) & 3 & 3 & 2 & \\
\hline EMS time (mean \pm SD) & $63 \pm 34$ & $70 \pm 30$ & $52 \pm 33$ & 0.07 \\
\hline \multicolumn{5}{|l|}{ Mode of transport } \\
\hline Ground EMS (\%) & 84 & 76 & 98 & \multirow[t]{2}{*}{0.001 for all } \\
\hline Air flight (\%) & 16 & 24 & 2 & \\
\hline ISS $($ mean \pm SD) & $27 \pm 10$ & $28 \pm 8$ & $27 \pm 10$ & 0.32 \\
\hline \multicolumn{5}{|l|}{ Scene data } \\
\hline Glasgow motor score (median) & $1(1-6)$ & $1(1-5)$ & $3(1-5)$ & 0.001 \\
\hline $\mathrm{O}_{2}$ saturation & $92 \pm 10$ & $91 \pm 11$ & $94 \pm 8$ & 0.16 \\
\hline $\mathrm{SBP}($ mean $\pm \mathrm{SD})$ & $133 \pm 32$ & $129 \pm 29$ & $142 \pm 40$ & 0.05 \\
\hline Pulse (mean \pm SD) & $93 \pm 30$ & $93 \pm 28$ & $92 \pm 30$ & 0.78 \\
\hline CT head (\%) & 91.5 & 89 & 100 & 0.009 \\
\hline Craniotomy (\%) & 14 & 6 & 25 & 0.001 \\
\hline Ventilator days (median) & $3(1-29)$ & $3(1-19)$ & $5(1-29)$ & 0.014 \\
\hline Hospital days (median) & $12(1-410)$ & $9(1-380)$ & $22(1-410)$ & 0.006 \\
\hline ICU LOS $($ mean $\pm S D)$ & $1(1-2)$ & $1(1-2)$ & $1(1-2)$ & 0.865 \\
\hline Pneumonia (\%) & 12 & 11.4 & 18.2 & 0.23 \\
\hline ARDS (\%) & 1.5 & 1.0 & 1.8 & 0.64 \\
\hline Blood alcohol level (median) & $44(7-93)$ & $38(27-64)$ & $43(7-66)$ & 0.926 \\
\hline \multicolumn{5}{|l|}{ ED disposition } \\
\hline Admitted to ICU (\%) & 81 & 85 & 86 & \multirow[t]{2}{*}{0.11 for all } \\
\hline Shifted to OR (\%) & 11 & 7 & 13 & \\
\hline Mortality (\%) & 46 & 54 & 31 & 0.005 \\
\hline
\end{tabular}

${ }^{*}$ Patients had head AIS $\geq 3$ and GCS $\leq 8$.

TABLE 2: Multivariate analysis for predictors of mortality among all intubated ISTBI cases.

\begin{tabular}{lcccc}
\hline Variables & $P$ value & OR & \multicolumn{2}{c}{$95 \%$ CI } \\
\hline Craniotomy (Yes versus No) & 0.864 & 0.907 & 0.297 & 2.774 \\
Scene motor GCS (reduced & 0.000 & 0.550 & 0.414 & 0.731 \\
versus not) & 0.338 & 0.630 & 0.245 & 1.620 \\
Mode of transport $^{*}$ & 0.157 & 0.552 & 0.242 & 1.256 \\
\hline Intubation location
\end{tabular}

ISTBI: isolated severe traumatic brain injury; ${ }^{*}$ ground versus air; ${ }^{* *} \mathrm{PHI}$ versus hospital.

injured patients. Moreover, PHI was found to be deleterious in many studies [7-12]. Consistent with these studies, our data showed around twofold increased rate of mortality in
PHI group compared to TRUI group. Murray et al. [7] also showed that patients with STBI requiring PHI had an increased mortality (81\%) when compared with nonintubated patients (43\%). The possible explanation for higher mortality rate is that majority of the patient in PHI group had higher incidence of penetrating injury and had higher head AIS and mean ISS. In addition, early death (within 48 hours) was not excluded, as those usually constitute the most lethal injuries.

Bochicchio et al. [9] studied prospectively 191 patients with STBI, after exclusion of those who died within the first 48 hours. Although, there were no significant differences in GCS, head AIS, and ISS between the two groups, PHI had a significantly greater mortality compared with patients intubated in the emergency department. PHI patients also were more likely to have died from complications such as 
TABLE 3: Review of literature for prehospital intubation studies in severe TBI patients.

\begin{tabular}{|c|c|c|c|c|}
\hline Authors & Definition criteria & Patient number & $\begin{array}{l}\text { Overall } \\
\text { mortality }\end{array}$ & Outcome \\
\hline Murray et al. 2000 [7] & $\begin{array}{l}\text { Severe TBI (field GCS }<8 \text { and } \\
\text { head AIS }>3 \text { ) }\end{array}$ & $\begin{array}{c}894 \text { TBI: } \\
\text { isolated TBI } \\
\quad(570)\end{array}$ & $47.2 \%$ & $\begin{array}{l}\text { Prehospital intubation failed to } \\
\text { demonstrate survival benefits in } \\
\text { patients with severe TBI. }\end{array}$ \\
\hline $\begin{array}{l}\text { Bochicchio et al. } 2003 \\
\text { [9] }\end{array}$ & $\begin{array}{l}\text { Severe TBI (GCS score } \leq 8 \text { and a } \\
\text { HAIS score } \geq 3 \text { ). Patients who } \\
\text { died within } 48 \text { hours of } \\
\text { admission were excluded }\end{array}$ & $\begin{array}{l}191 \text { TBI: isolated } \\
\text { TBI (68) }\end{array}$ & $16.8 \%$ & $\begin{array}{l}\text { PHI had significantly increased } \\
\text { mortality ( } 23 \% \text { versus } 12.4 \% \text {, } \\
P=0.05) \text {. Also, the risk of mortality } \\
\text { was } 1.85 \text { times higher in PHI group } \\
\text { compared to ED intubated patients. }\end{array}$ \\
\hline Wang et al. 2004 [19] & Severe TBI (head/neck AIS $\geq 3$ ) & 4098 & $37 \%$ & $\begin{array}{l}\text { PHI is associated with increased risk of } \\
\text { mortality (OR } 3.99 ; 95 \% \text { CI } 3.21 \text { to } \\
4.93 \text { ) and poor neurologic outcome } \\
\text { (OR } 1.61 ; 95 \% \text { CI } 1.15 \text { to } 2.26 \text { ). }\end{array}$ \\
\hline $\begin{array}{l}\text { Vandromme et al. } 2011 \\
{[20]}\end{array}$ & $\begin{array}{l}\text { Severe TBI (prehospital GCS } \\
\text { score } \leq 8 \text { ) }\end{array}$ & 149 & $46.9 \%$ & $\begin{array}{l}\text { PH intubation is associated with severe } \\
\text { TBI but had no increased risk for } \\
\text { mortality over ED intubation. }\end{array}$ \\
\hline Warner et al. 2007 [21] & $\begin{array}{l}\text { Severe TBI (head AIS score }>3 \text { ), } \\
\text { isolated TBI (head AIS score }>3 \\
\text { but no other AIS score }>2 \text { ) }\end{array}$ & $\begin{array}{l}187 \text { TBI: isolated } \\
\text { TBI (95) }\end{array}$ & $24.4 \%$ & $\begin{array}{l}\text { Targeted PHI is associated with lower } \\
\text { mortality after severe TBI. }\end{array}$ \\
\hline $\begin{array}{l}\text { Winchell and Hoyt } \\
1997 \text { [6] }\end{array}$ & Head $\mathrm{AIS} \geq 4$ and GCS $\leq 8$ & $\begin{array}{l}671 \text { TBI: isolated } \\
\text { TBI (351) }\end{array}$ & $57 \%$ & $\begin{array}{l}\text { Field intubation reduced mortality } \\
\text { from } 57 \% \text { to } 36 \% \text { in patients with } \\
\text { severe TBI and from } 50 \% \text { to } 23 \% \text { in } \\
\text { isolated TBI }\end{array}$ \\
\hline Davis et al. 2005 [22] & $\begin{array}{l}\text { Moderate to severe TBI } \\
\text { (head/neck AIS score of } \geq 3 \text { ). }\end{array}$ & 13,625 & $22.9 \%$ & $\begin{array}{l}\text { PHI is associated with increased } \\
\text { mortality ( } 55 \% \text { versus } 15 \%) \text { in } \\
\text { comparison to nonintubated patients } \\
\text { with moderate to severe TBI. }\end{array}$ \\
\hline Present study & $\begin{array}{l}\text { Field GCS } \leq 8 \text { and head AIS } \geq 3 \text {. } \\
\text { Patients who died within first } 24 \\
\text { hours were excluded }\end{array}$ & $\begin{array}{l}160 \text { isolated } \\
\text { severe TBI }\end{array}$ & $46 \%$ & $\begin{array}{l}\text { No added benefit in PHI group. Scene } \\
\text { motor GCS (OR 0.55; } 95 \% \text { CI } \\
0.41-0.73 \text { ) had a significant association } \\
\text { with mortality. }\end{array}$ \\
\hline
\end{tabular}

PHI: Prehospital intubations; TBI: traumatic brain injuries; GCS: Glasgow Coma Scale score; AIS: Abbreviated Injury Scale; ED: emergency department.

respiratory failure. However, our study showed no significant difference in rates of pneumonia and ARDS between the two groups.

On the other hand, survival benefit was demonstrated in a study conducted by Winchell and Hoyt [6]. PHI was associated with dramatic improved survival in patients with isolated STBI (from $50 \%$ to $23 \%$ ), and that effect was more pronounced after exclusion of lethal injuries with GCS of 3. However, in that study, the analysis did not adjust for potentially important factors such as hypotension or hypoxia to validate the hypothesis that prevention of secondary insult was attributed to this positive outcome.

Davis et al. [22] studied the impact of prehospital intubation on outcome using large database of head injured patients. The authors concluded that patients with head AIS $\geq 4$ and/or GCS of 3-8 had a higher mortality rate, if they were intubated in pre-hospital setting compared to emergency department intubation (63\% versus 36\%, $P=0.001)$.

Although the present study was not intended to examine the effects of mode of transportation on patient's outcome, most head injured patients were transferred by ground transportation, while the percentage of pre-hospital intubation was significantly higher in the air flights. This was attributed to many factors discussed in previous studies, such as severity of injury, training of paramedics, and time factor during transfer [24]. Recent studies have demonstrated improved safety and effectiveness with doctor delivered PHI compared to the paramedical staff [25-27]. However, in Qatar, highly trained critical care paramedics are delivering prehospital critical care services. Our analysis addresses the controversial issue of PHI in head injury cases and this may pave the way for further improvement of EMS services.

Limitations. The limitations of this study include its retrospective design, as it was based on administrative data that lacks many points to capture, such as number of attempted or failed intubations, duration of the intubation attempt, and use of medications. No disability data are available to determine the long-term functional outcome of survivors. Possibility of survival bias is present in favor of in-hospital intubation as the patient population being compared is not truly identical. 
We tried to avoid the later by excluding early mortality cases, as they constitute the most lethal injuries.

\section{Conclusion}

Prehospital intubation continues to be a controversial issue. In isolated STBI based on AIS, PHI is associated with (but not cause of) a worse outcome in comparison to in-hospital intubation. PHI may be a marker for high risk in selected trauma population. So, more studies are needed for in-depth analysis for the lack of benefit of prehospital in this group of patients.

\section{Conflict of Interests}

The authors declare that they have no competing interests and no financial issues to disclose.

\section{Authors' Contribution}

Mazen Tuma designed the study, collected data, and drafted the paper, Ayman El-Menyar designed the study, analyzed data, and reviewed the manuscript, Hassan AlThani assisted with the design of the study and drafted the manuscript, Husham Abdulrahman collected data and drafted manuscript, Ahmad Zarour collected data and drafted manuscript, Ashok Parchani collected data and drafted manuscript, Sherwan Khashnaw collected data and drafted manuscript, and Rifat Latifi assisted with the design of the study and reviewed manuscript. All the authors have read and approved the manuscript.

\section{Acknowledgments}

The authors acknowledge the support and outstanding effort of Ms Monira Mullazahi and trauma registry database team.

\section{References}

[1] D. P. Davis, K. M. Koprowicz, C. D. Newgard et al., "The relationship between out-of-hospital airway management and outcome among trauma patients with glasgow coma scale scores of 8 or less," Prehospital Emergency Care, vol. 15, no. 2, pp. 184192, 2011.

[2] R. M. Chesnut, L. F. Marshall, M. R. Klauber et al., "The role of secondary brain injury in determining outcome from severe head injury," Journal of Trauma, vol. 34, no. 2, pp. 216-222, 1993.

[3] F. A. Pigula, S. L. Wald, S. R. Shackford, and D. W. Vane, “The effect of hypotension and hypoxia on children with severe head injuries," Journal of Pediatric Surgery, vol. 28, no. 3, pp. 310-316, 1993.

[4] N. Stocchetti, A. Furlan, and F. Volta, "Hypoxemia and arterial hypotension at the accident scene in head injury," Journal of Trauma-Injury, Infection and Critical Care, vol. 40, no. 5, pp. 764-767, 1996.

[5] E. R. Kokoska, G. S. Smith, T. Pittman, and T. R. Weber, "Early hypotension worsens neurological outcome in pediatric patients with moderately severe head trauma," Journal of Pediatric Surgery, vol. 33, no. 2, pp. 333-338, 1998.
[6] R. J. Winchell and D. B. Hoyt, "Endotracheal intubation in the field improves survival in patients with severe head injury," Archives of Surgery, vol. 132, no. 6, pp. 592-597, 1997.

[7] J. A. Murray, D. Demetriades, T. V. Berne et al., "Prehospital intubation in patients with severe head injury," Journal of Trauma-Injury, Infection and Critical Care, vol. 49, no. 6, pp. 1065-1070, 2000.

[8] Z. T. Stockinger and N. E. McSwain Jr., "Prehospital endotracheal intubation for trauma does not improve survival over bagvalve-mask ventilation," Journal of Trauma-Injury, Infection and Critical Care, vol. 56, no. 3, pp. 531-536, 2004.

[9] G. V. Bochicchio, O. Ilahi, M. Joshi, K. Bochicchio, and T. M. Scalea, "Endotracheal intubation in the field does not improve outcome in trauma patients who present without an acutely lethal traumatic brain injury," Journal of TraumaInjury, Infection and Critical Care, vol. 54, no. 2, pp. 307-311, 2003.

[10] M. Eckstein, L. Chan, A. Schneir, and R. Palmer, "Effect of prehospital advanced life support on outcomes of major trauma patients," Journal of Trauma-Injury, Infection and Critical Care, vol. 48, no. 4, pp. 643-648, 2000.

[11] D. P. Davis, D. B. Hoyt, M. Ochs et al., "The effect of paramedic rapid sequence intubation on outcome in patients with severe traumatic brain injury," Journal of Trauma-Injury, Infection and Critical Care, vol. 54, no. 3, pp. 444-453, 2003.

[12] T. F. Vadeboncoeur, D. P. Davis, M. Ochs, J. C. Poste, D. B. Hoyt, and G. M. Vilke, "The ability of paramedics to predict aspiration in patients undergoing prehospital rapid sequence intubation," Journal of Emergency Medicine, vol. 30, no. 2, pp. 131-136, 2006.

[13] W. P. Bozeman and A. H. Idris, "Intracranial pressure changes during rapid sequence intubation: a swine model," Journal of Trauma-Injury, Infection and Critical Care, vol. 58, no. 2, pp. 278-283, 2005.

[14] D. P. Davis, A. H. Idris, M. J. Sise et al., "Early ventilation and outcome in patients with moderate to severe traumatic brain injury," Critical Care Medicine, vol. 34, no. 4, pp. 1202-1208, 2006.

[15] D. P. Davis, W. Meade Jr., M. J. Sise et al., "Both hypoxemia and extreme hyperoxemia may be detrimental in patients with severe traumatic brain injury," Journal of Neurotrauma, vol. 26, no. 12, pp. 2217-2223, 2009.

[16] M. Helm, J. Hauke, and L. Lampl, "A prospective study of the quality of pre-hospital emergency ventilation in patients with severe head injury," British Journal of Anaesthesia, vol. 88, no. 3, pp. 345-349, 2002.

[17] C. Healey, T. M. Osler, F. B. Rogers et al., "Improving the Glasgow Coma Scale score: motor score alone is a better predictor," Journal of Trauma-Injury, Infection and Critical Care, vol. 54, no. 4, pp. 671-680, 2003.

[18] "Guidelines for the management of severe traumatic brain injury, 3rd edition," Journal of Neurotrauma, vol. 24, supplement 1, 2007.

[19] H. E. Wang, A. B. Peitzman, L. D. Cassidy, P. D. Adelson, and D. M. Yealy, "Out-of-hospital endotracheal intubation and outcome after traumatic brain injury," Annals of Emergency Medicine, vol. 44, no. 5, pp. 439-450, 2004.

[20] M. J. Vandromme, S. M. Melton, R. Griffin et al., "Intubation patterns and outcomes in patients with computed tomographyverified traumatic brain injury," Journal of Trauma-Injury, Infection and Critical Care, vol. 71, no. 6, pp. 1615-1619, 2011.

[21] K. J. Warner, J. Cuschieri, M. K. Copass, G. J. Jurkovich, and E. M. Bulger, "The impact of prehospital ventilation on outcome 
after severe traumatic brain injury," Journal of Trauma-Injury, Infection and Critical Care, vol. 62, no. 6, pp. 1330-1338, 2007.

[22] D. P. Davis, J. Peay, M. J. Sise et al., “The impact of prehospital endotracheal intubation on outcome in moderate to severe traumatic brain injury," Journal of Trauma-Injury, Infection and Critical Care, vol. 58, no. 5, pp. 933-939, 2005.

[23] E. M. Bulger, A. B. Nathens, F. P. Rivara, M. Moore, E. J. MacKenzie, and G. J. Jurkovich, "Management of severe head injury: institutional variations in care and effect on outcome," Critical Care Medicine, vol. 30, no. 8, pp. 1870-1876, 2002.

[24] E. M. Bulger, D. Guffey, F. X. Guyette et al., "Resuscitation outcomes consortium investigators. Impact of prehospital mode of transport after severe injury: a multicenter evaluation from the resuscitation outcomes consortium," Journal of Trauma and Acute Care Surgery, vol. 72, no. 3, pp. 567-573, 2012.

[25] L. Raatiniemi, S. Länkimäki, and M. Martikainen, "Pre-hospital airway management by non-physicians in Northern Finlanda cross-sectional survey," Acta Anaesthesiologica Scandinavica, vol. 57, no. 5, pp. 654-659, 2013.

[26] M. Helm, G. Kremers, L. Lampl, and B. Hossfeld, "Incidence of transient hypoxia during pre-hospital rapid sequence intubation by anaesthesiologists," Acta Anaesthesiologica Scandinavica, vol. 57, no. 2, pp. 199-205, 2013.

[27] H. M. Lossius, J. Røislien, and D. J. Lockey, "Patient safety in pre-hospital emergency tracheal intubation: a comprehensive meta-analysis of the intubation success rates of EMS providers," Critical Care, vol. 16, no. 1, article R24, 2012. 


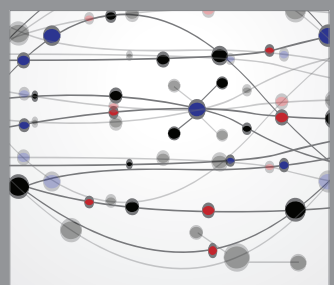

The Scientific World Journal
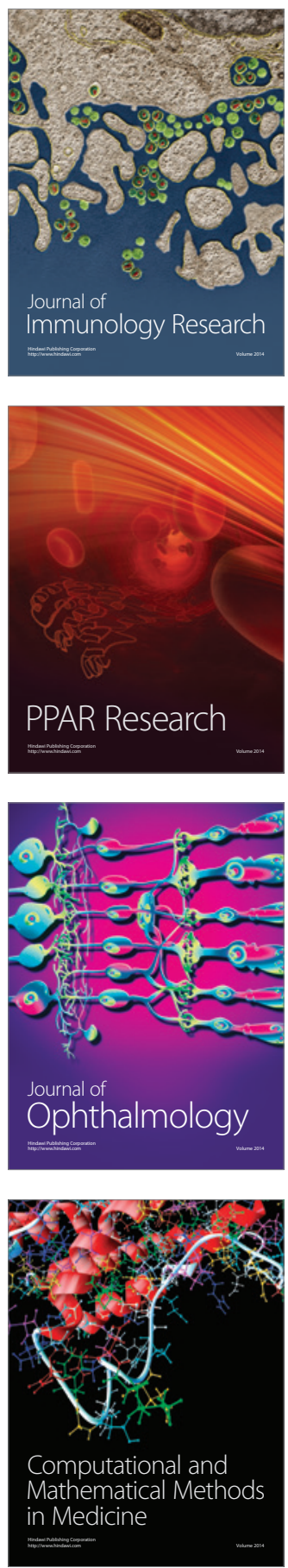

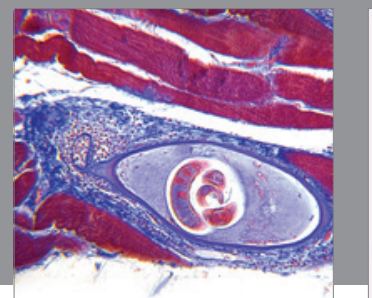

Gastroenterology

Research and Practice
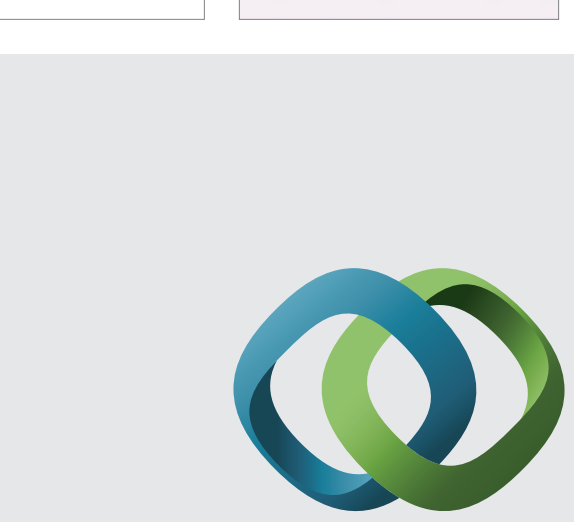

\section{Hindawi}

Submit your manuscripts at

http://www.hindawi.com
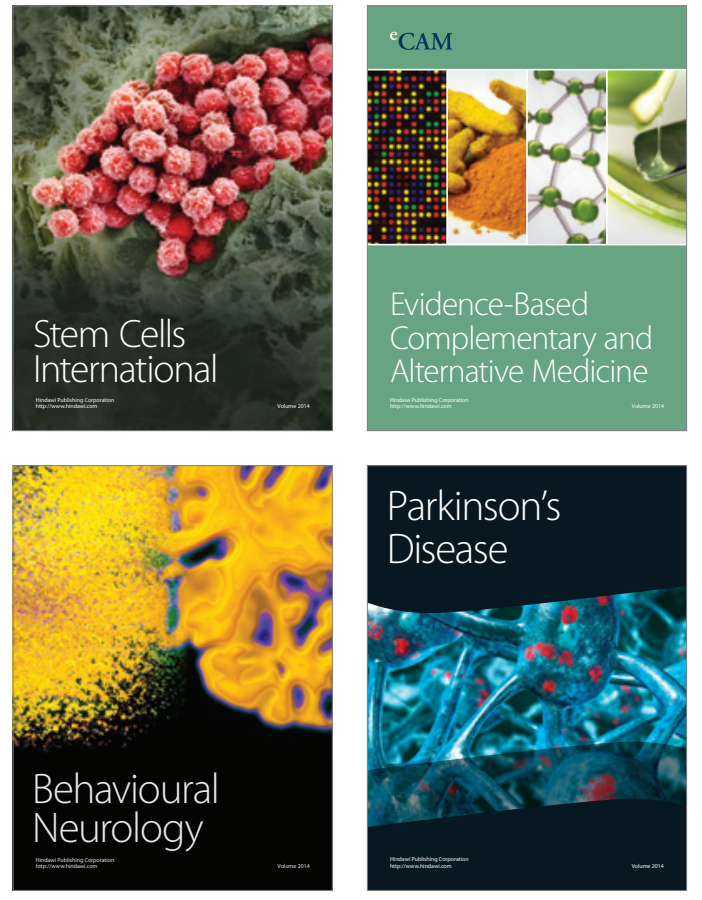
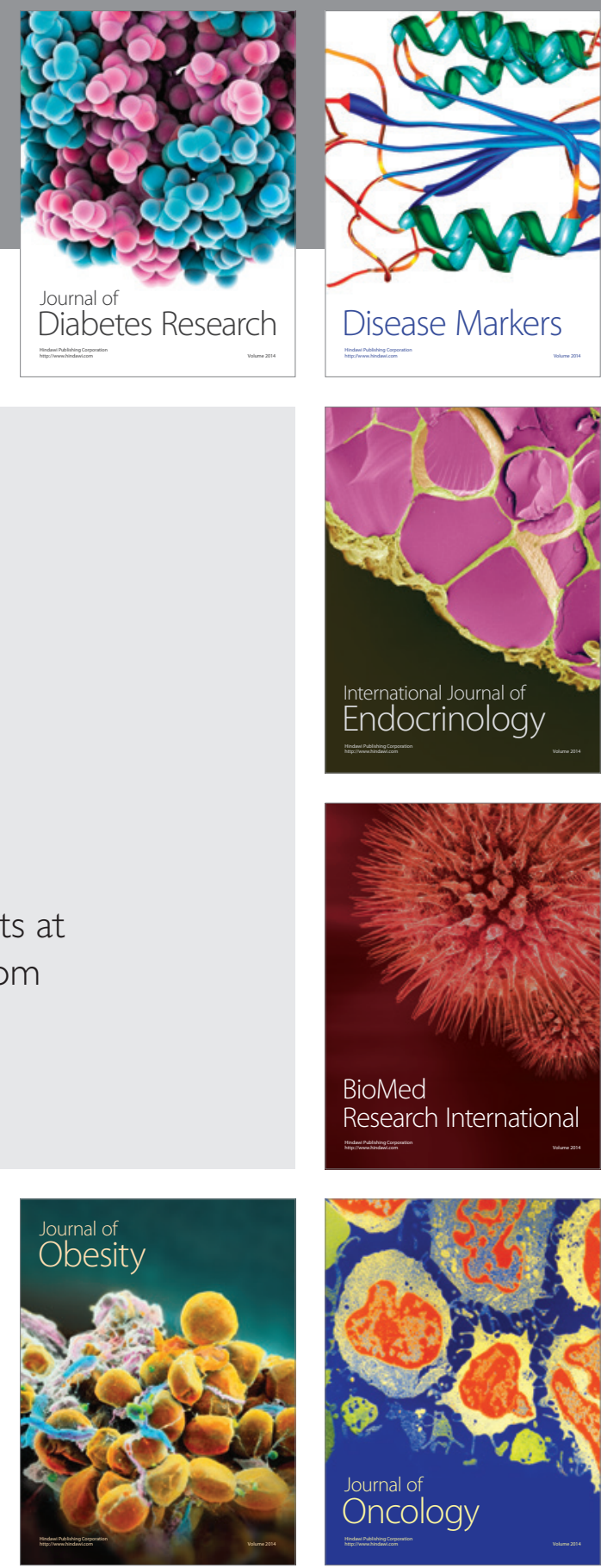

Disease Markers
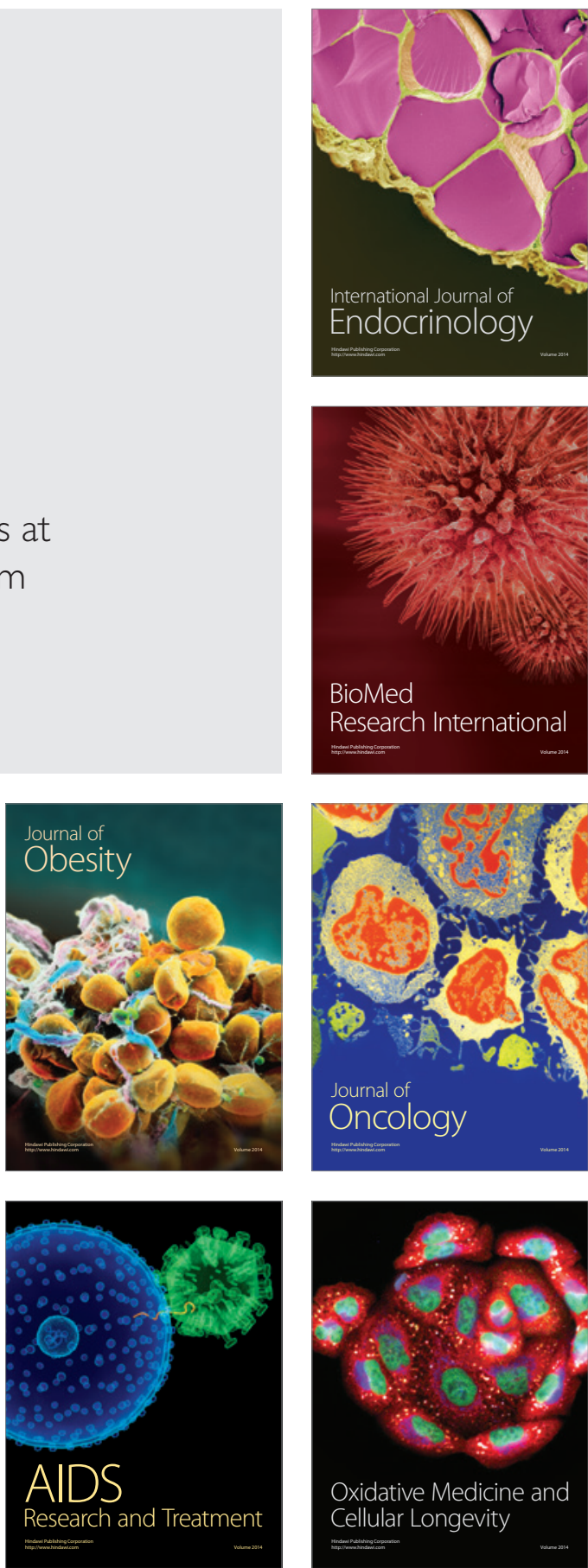